\title{
O PROCESSO DE CRIAÇÃO POÉTICA
}

\section{THE PROCESS OF POETIC CREATION}

\section{Norberto PERKOSKI ${ }^{47}$}

\begin{abstract}
RESUMO: Partindo de um dos diálogos de Platão, Íon, em que Sócrates questiona o rapsodo que dá título à obra, passando pelo ensaio "A filosofia da composição", de Edgar Allan Poe, no qual o escritor detalha o processo de criação de "O corvo" e atingindo poetas modernistas e contemporâneos, apresentam-se posicionamentos acerca do fazer poético. Entre a musa inspiradora e a objetividade racional, movem-se depoimentos dos criadores, bem como poemas em que a metalinguagem se faz presente em relação ao tema. Assim, constata-se que a questão do poeta inspirado ou do poeta artífice perpassa os séculos, instituindo-se como um dos aspectos mais intrigantes a que os criadores são chamados a dar uma resposta.
\end{abstract}

PALAVRAS-CHAVE: Criação poética; Inspiração; Racionalidade; Metalinguagem.

ABSTRACT: Based on one of the dialogues of Plato, Ion, in which Socrates questions the rhapsode, who is the title character of the work, going through the essay "The philosophy of composition" by Edgar Allan Poe, where the writer gives details about the process of creating "The Raven" and affecting modern and contemporary poets, positions regarding poetic creation are presented. Among the inspiring muse and the rational objectivity, move testimonials of the creators, as well as poems where the metalanguage is present in the topic. So, it seems that the issue of the inspired poet or the craftsman poet goes through the centuries, establishing one of the most intriguing aspects that creators are asked to provide an answer.

KEYWORDS: Poetic creation; Inspiration; Rationality; Metalanguage.

Inevitavelmente, em algum momento de sua vida, os criadores, entre eles os poetas, são questionados acerca de como procedem durante o processo de criação de suas obras. Essa questão perpassa os séculos e intriga tanto o artista, que é instado a dar-lhe uma

47 Professor da Graduação e do Mestrado em Letras da Universidade de Santa Cruz do Sul (UNISC), CEP 96815-900, Santa Cruz do Sul, RS, Brasil, perkoski@unisc.br 
resposta, quanto o fruidor que tem curiosidade em saber acerca de como ocorre a realização de algo que, do inexistente, passa a integrar o contexto cultural.

Duas correntes geralmente são mencionadas: o poeta inspirado, veículo de manifestação das palavras da musa, e o poeta artífice, que se coloca na situação de um trabalhador pessoal da linguagem.

No diálogo Íon, de Platão, essa questão central é abordada e indaga-se acerca da criação poética, se ela é resultado da arte (no texto como sinônimo de técnica) ou da inspiração.

O diálogo entre o filósofo e Íon, o rapsodo, inicia com o primeiro questionando se o último estaria vindo de sua terra natal, Éfeso; ao que ele responde que estava voltando de Epidauro, onde haviam ocorrido as festas em honra a Asclépio, deus da medicina, filho de Apolo. Sócrates interroga se é verdade que os habitantes de Epidauro organizam um concurso de rapsodos em honra desse deus. Ao que Íon responde que ocorrem concursos “em honra de todas as artes das Musas" (PLATÃO, 1988, p. 23). Sócrates então pergunta a Íon se ele havia participado da prova e como ele tinha se saído. Íon responde que havia vencido a prova.

Sócrates declara sentir inveja dos rapsodos, pois estes "têm necessidade de estar bem familiarizados com muitos e bons poetas - e principalmente com Homero, o melhor e mais divino de todos - e de aprofundar o pensamento e não apenas as palavras" (PLATÃO, 1988, p. 25). Como Íon afirma que de todos os rapsodos ele é quem conhece melhor Homero, Sócrates incita-o a prová-lo. Íon gaba-se de ter embelezado Homero, que vale a pena ouvi-lo e que, por isso, mereceria ser coroado com uma coroa de ouro.

Sócrates questiona se Íon é especialista só de Homero ou também de outros poetas. Íon responde que exclusivamente de Homero. Através de uma série de questionamentos - o método socrático - o filósofo leva Íon a cair em contradição e conclui:

Então, meu caríssimo amigo, não erraremos ao afirmar que Íon é tão bom especialista de Homero como dos outros poetas, porque é ele próprio que afirma que um mesmo e único homem será juiz competente de todos os que falam sobre as mesmas coisas e, por outro lado, quase todos os poetas tratam os mesmos temas. (PLATÃO, 1988, p. 39). 
Em sua elucidativa abordagem na obra Platão: as artimanhas do fingimento (1999), Maria Cristina Franco Ferraz, no capítulo "O poeta, como o sofista: um fingidor”, esclarece que, para abordar a questão da mimesis, o filósofo discute não com um verdadeiro poeta, mas com um rapsodo, um recitador de obras alheias, portanto não um porta-voz das musas. Segundo a autora, Sócrates encaminha os seus questionamentos a Íon com o objetivo de desmerecer a poesia, valorizando o $\operatorname{logos}$ filosófico. A autora acentua também na sua análise a total incompetência do rapsodo, presa fácil das estratégias argumentativas do pensador.

No diálogo, Sócrates tem como objetivo alcançar a anuência de Íon de que ele recita Homero não por arte, ou seja, por técnica e, sim, por inspiração:

É que esse dom que tu tens de falar sobre Homero não é uma arte, como disse ainda agora, mas uma força divina, que te move, tal como a pedra a que Eurípedes chamou de Magnésia e que a maior parte das pessoas chama pedra de Heracleia. [...] Assim, também a Musa inspira ela própria e, através destes inspirados, forma-se uma cadeia, experimentando outros o entusiasmo. Na verdade, todos os poetas épicos, os bons poetas, não é por efeito de arte, mas porque são inspirados e possuídos, que eles compõem todos esses belos poemas; [...]. (PLATÃO, 1988, p. 49-51, grifo do autor).

Quanto aos poetas líricos, Sócrates tem o mesmo posicionamento:

[...] os bons poetas líricos, tal como os Coribantes não dançam senão quando estão fora de si, também os poetas líricos não estão em si quando compõem esses belos poemas; mas, logo que entram na harmonia e no ritmo, são transformados e possuídos como as Bacantes que, quando estão possuídas, bebem nos rios o leite e o mel, mas não, quando estão na sua razão, e é assim a alma dos poetas líricos, segundo eles dizem. [...] o poeta é uma coisa leve, alada, sagrada, e não pode criar antes de sentir a inspiração, de estar fora de si e de perder o uso da razão. Enquanto não receber este dom divino, nenhum ser humano é capaz de fazer versos ou de proferir oráculos. (PLATÃO, 1988, p. 51).

E, mais adiante, reitera:

[...] estes belos poemas não são humanos nem são obras de homens, mas que são divinos e dos deuses, e que os poetas não passam de intérpretes dos deuses, sendo possuídos pela divindade, de quem recebem a inspiração. (PLATÃO, 1988, p. 55). 
Como Íon argumenta que é "por um privilégio divino que os bons poetas são os intérpretes dos deuses" (PLATÃO, 1988, p. 55), Sócrates questiona se os rapsodos interpretam as obras dos poetas, com o que Íon concorda, ao que o filósofo conclui que os rapsodos são intérpretes de intérpretes, imitadores, portanto, de segunda ordem.

Quanto ao envolvimento do rapsodo no momento da recitação, Sócrates mais uma vez interroga:

[...] Quando declamas adequadamente versos épicos e impressionas profundamente os espectadores, [...] estás na posse da tua razão? Ou estás fora de ti e a tua alma no transporte do entusiasmo? (PLATÃO, 1988, p. $57)$.

Ao que Íon responde: “Com efeito, quando recito um passo patético, os meus olhos enchem-se de lágrimas; se é assustador e terrível, os cabelos eriçam-se-me e o coração bate-me mais depressa" (PLATÃO, 1988, p. 59). No entanto, a entrega não é plena, uma vez que ele também manifesta preocupação com a reação do público: “É necessário, com efeito, que os observe bem: se os fizer chorar, eu rirei quando receber o dinheiro, enquanto que, se rirem, chorarei eu ao perder o meu salário" (PLATÃO, 1988, p. 61).

Quanto à reação do público, Sócrates retoma a imagem de conectividade que a pedra de Magnésia provoca:

Vês, agora, que esse espectador é o último dos anéis de que falei. [...] O do meio és tu, rapsodo e actor; o primeiro, o próprio poeta. $\mathrm{E}$ a divindade, através de todos estes, atrai onde quer a alma dos homens [...]. Este poeta liga-se a uma Musa, aquele a uma outra - e chama-se a isso ser possuído. (PLATÃO, 1988, p. 61).

No polo oposto ao do poeta inspirado, situa-se o poeta artífice, aquele que elabora a sua criação através de um processo de pensamento que faz uso da razão, que invade o seu próprio texto, alterando-o por meio de correções ou acrescentando-lhe novos elementos. Um dos textos teóricos clássicos, talvez o que melhor represente essa corrente, é o estudo "A filosofia da composição", de Edgar Allan Poe. "Filosofia" deve ser entendida, aqui, como um "conjunto de princípios” norteadores do processo de criação da obra. 
No ensaio, Poe se embasa no seu próprio fazer literário. Tanto em relação à narrativa, ao conto especificamente, quanto ao poema, o escritor norte-americano defende a importância do final do texto:

Só tendo o epílogo constantemente em vista, poderemos dar a um enredo seu aspecto indispensável de consequência, ou causalidade, fazendo com que os incidentes, especialmente, o tom da obra tendam para o desenvolvimento de sua intenção. (POE, 1985, p. 101, grifo do autor).

Poe acentua também a relevância, desde o início da elaboração do texto, de se ter como objetivo principal a provocação de uma reação no leitor:

Eu prefiro começar com a consideração de um efeito. Mantendo sempre a originalidade em vista [...], digo-me em primeiro lugar: "Dentre os inúmeros efeitos, ou impressões a que são suscetíveis o coração, a inteligência ou, mais geralmente, a alma, qual irei eu, na ocasião atual, escolher?" (POE, 1985, p. 102, grifos do autor).

A seguir, faz uma crítica contundente aos poetas que se dizem inspirados:

Muitos escritores - especialmente os poetas - preferem ter por entendido que compõem por meio de uma espécie de sutil frenesi, de intuição estática; e positivamente estremeceriam ante a ideia de deixar o público dar uma olhadela, por trás dos bastidores, para as rudezas vacilantes e trabalhosas do pensamento, para os verdadeiros propósitos só alcançados no último instante, para os inúmeros relances de ideias que não chegam à maturidade da visão completa, para as imaginações plenamente amadurecidas e repelidas em desespero como inaproveitáveis, para as cautelosas seleções e rejeições, as dolorosas emendas e interpolações; numa palavra, para as rodas e rodinhas, os apetrechos de mudança do cenário, as escadinhas e os alçapões do palco, as penas de galo, a tinta vermelha e os disfarces postiços que, em noventa e nove por cento dos casos, constituem a característica do histrião literário.

Bem sei, de outra parte, que de modo algum é comum o caso em que um autor esteja absolutamente em condições de reconstituir os passos pelos quais suas conclusões foram atingidas. As sugestões, em geral, tendo-se erguido em tumulto, são seguidas e esquecidas de maneira semelhante. (POE, 1985, p. 102-103, grifo do autor).

Aproveitando a metáfora do "palco", Poe se propõe a mostrar "os bastidores" da construção de seu fazer poético: 
Quanto a mim, nem simpatizo com a repugnância acima aludida nem, em qualquer tempo, tive a menor dificuldade em relembrar os passos progressivos de qualquer de minhas composições; e, [...] não se deve encarar, como falta de decoro de minha parte, o mostrar o modus operandi pelo qual uma de minhas próprias obras se completou. Escolhi "O Corvo", como a mais geralmente conhecida. É meu desígnio tornar manifesto que nenhum ponto de sua composição se refere ao acaso, ou à intuição, que o trabalho caminhou, passo a passo, até completar-se, com a precisão e a sequência rígida de um problema matemático. (POE, 1985, p. 103).

$\mathrm{Na}$ sequência, Poe apresenta o processo de criação de sua obra, previamente elaborado. $\mathrm{O}$ escritor esclarece acerca de suas decisões quanto à extensão do texto, ao efeito pretendido, ao tom, ao refrão com a escolha da palavra nervermore e do animal que a enuncia, ao tema, ao clímax, aos aspectos formais do ritmo e do metro, bem como acerca da eleição do busto de Minerva, onde o corvo pousa.

Conquanto seja difícil aceitar que todo o processo de elaboração do poema tenha sido pensado tão metodicamente antes de sua consecução, o ensaio de Poe instituiu-se como texto paradigmático do poeta artífice.

No século XX, renova-se a oposição com o poeta inspirado através do advento da Psicanálise, e a antiga musa recebe um outro nome: inconsciente. Na esteira freudiana, André Breton conceitua o termo que terá uma ampla repercussão no âmbito das artes:

SURREALISMO, n.m. Automatismo psíquico pelo qual alguém se propõe a exprimir seja verbalmente, seja por escrito, seja de qualquer outra maneira, o funcionamento real do pensamento. Ditado do pensamento, na ausência de todo controle exercido pela razão, fora de qualquer preocupação estética ou moral. (BRETON, 2002, p. 191).

Na literatura, o propósito surrealista redundou na "escrita automática", ou seja, na busca do registro indiscriminado de ideias, sonhos e sensações, sem qualquer censura racional.

Antes mesmo da publicação do manifesto surrealista, em 1924, Mário de Andrade já contemplava, em seu processo de criação artística, elementos oriundos do inconsciente, sem descuidar do pensamento racional, aproveitando-se tanto de um quanto de outro. Em um dos fragmentos do "Prefácio interessantíssimo", abertura que se poderia chamar de teóricocrítica de sua obra Pauliceia desvairada, de 1922, afirma: 
Quando sinto a impulsão lírica escrevo sem pensar tudo o que meu inconsciente me grita. Penso depois: não só para corrigir, como para justificar o que escrevi. Daí a razão deste Prefácio Interessantíssimo. (ANDRADE, 1987, p. 59).

$\mathrm{Na}$ corrente exclusiva da racionalidade como processo de criação poética, João Cabral de Melo Neto é um autor paradigmático. Através da metalinguagem como, por exemplo, nos poemas "O engenheiro", "A palo seco", "Psicologia da composição" (em especial o de número VI) e "Graciliano Ramos", o poeta defende a elaboração do texto como produto exclusivo da razão, o que também se pode comprovar através de um de seus depoimentos:

Eu não acredito em inspiração e nem sou poeta inspirado. $O$ ato de criação para mim é intelectual. Minha poesia trabalha a criação e a construção. Acredito na expiração. Na composição de um poema, primeiro me ocorre um tema e eu tomo nota. Depois vou estudando-o e desenvolvendo-o. Nunca escrevi um poema inspirado, soprado pelo Espírito Santo. Isso eu não sei o que é... (MELO NETO, 2007, p. 139).

Já como exemplo do polo oposto, na origem do poema, pode-se situar a poetisa portuguesa Sophia de Mello Breyner Andresen, em seu texto "Arte poética IV", do qual apresenta-se um fragmento extenso, mas necessário:

Fernando Pessoa dizia: "Aconteceu-me um poema". A minha maneira de escrever fundamental é muito próxima deste "acontecer". O poema aparece feito, emerge, dado (ou como se fosse dado). Como um ditado que escuto e noto.

E possível que esta maneira esteja em parte ligada ao facto de, na minha infância, muito antes de eu saber ler, me terem ensinado a decorar poemas. Encontrei a poesia antes de saber que havia literatura. Pensava que os poemas não eram escritos por ninguém, que existiam em si mesmos, por si mesmos, que eram como que um elemento do natural, que estavam suspensos, imanentes. E que bastaria estar muito quieta, calada e atenta para os ouvir.

Desse encontro inicial ficou em mim a noção de que fazer versos é estar atento e de que o poeta é um escutador.

É difícil descrever o fazer de um poema. Há sempre uma parte que não consigo distinguir, uma parte que se passa na zona onde eu não vejo.

Sei que o poema aparece, emerge e é escutado num equilíbrio especial da atenção, numa tensão especial da concentração. O meu esforço é para conseguir ouvir o "poema todo" e não apenas um fragmento. Para ouvir o 
"poema todo" é necessário que a atenção não se quebre ou atenue e que eu própria não intervenha. É preciso que eu deixe o poema dizer-se. Sei que quando o poema se quebra, como um fio no ar, o meu trabalho, a minha aplicação não conseguem continuá-lo.

Como, onde e por quem é feito esse poema que acontece, que aparece como já feito? A esse "como, onde e quem" os antigos chamavam Musa. É possível dar-lhe outros nomes e alguns lhe chamarão subconsciente, um subconsciente acumulado, enrolado sob si próprio com um filme que de repente, movido por qualquer estímulo, se projeta na consciência como num écran. Por mim, é-me difícil nomear aquilo que não distingo bem. Éme difícil, talvez impossível, distinguir se o poema é feito por mim, em zonas sonâmbulas de mim, ou se é feito em mim por aquilo que em mim se inscreve. Mas sei que o nascer do poema só é possível a partir daquela forma de ser, estar e viver que me torna sensível - como a película de um filme - ao ser e ao aparecer das coisas. E a partir de uma obstinada paixão por esse ser e aparecer.

Deixar que o poema se diga por si, sem intervenção minha (ou sem intervenção que eu veja), como quem segue um ditado (que ora é mais nítido, ora mais confuso), é a minha maneira de escrever. (ANDRESEN, 2004, p.213-214).

Não se afasta muito desse processo o teórico da literatura Emil Staiger, quando aborda o gênero lírico, na obra Conceitos fundamentais da poética:

O poeta lírico não produz coisa alguma. Ele abandona-se - literalmente (Stimmung) - à inspiração. Ele inspira ao mesmo tempo clima e linguagem. Não tem condições de dirigir-se a um nem a outra. Seu poetar é involuntário. [...] O poeta lírico escuta sempre de novo em seu íntimo os acordes já uma vez entoados, recria-os, como os cria também no leitor. Finalmente reconquista o já perdido encantamento da inspiração, ou dá pelo menos um cunho de involuntariedade a sua obra, como o fazem também muitos poetas de épocas decadentes, herdeiros deste legado útil. (STAIGER, 1993, p.28)

A seguir, já encaminhando o término desta exposição, apresentam-se depoimentos, coletados por José Domingos de Brito (2007). O primeiro de Carlos Drummond de Andrade:

Eu sou inteiramente partidário da ideia da inspiração. Seja banal, antiquado, mas sem inspiração não se faz nem se escreve nada. A pessoa adquire a técnica de se comunicar e tem facilidade, como eu tenho, de escrever coisas. Mas aquela coisa profunda que vem das entranhas da gente, isto é inspiração... (ANDRADE, 2007, p. 76). 
O segundo de Anderson Braga Horta:

Parto do que chamamos inspiração (embora nem sempre espere por uma centelha mágica...), que, todavia, não prescinde das técnicas de construção, sua contraparte intelectual. $\mathrm{Na}$ verdade, inspiração e construção imbricam-se, são aspectos de um ato unitário - o fazer poético. Não sei dizer qual dos dois aspectos predomina em mim. (HORTA, 2007, p. 44).

O posicionamento da última citação parece ser o mais comum entre os poetas contemporâneos. A tensão entre o poeta inspirado e o poeta artesão encontra na síntese dialética, que não descarta nenhum dos elementos antitéticos, a via de expressão mais clarificadora do processo de criação poética.

O enigma da criação poética é um dos aspectos que mais intriga o público, daí por que é uma das perguntas mais frequentes dos leitores aos escritores. Tal atitude parece advir do fato de que, como afirma Bachelard, na obra A poética do espaço (1988, p. 10), o leitor, quando intensamente envolvido pelo poema, torna-se o "fantasma do escritor", sentindo que ele, leitor, se tivesse a técnica, poderia ter escrito o poema.

Para encerrar, apresenta-se um comentário de Moacyr Scliar que, embora vindo de um prosador, pode ser generalizado a todos os criadores, independentemente do gênero:

Duas perguntas são feitas frequentemente a escritores. A primeira delas: de onde vêm as ideias para os textos? A segunda: como é o seu processo de criação literária? Diga-se desde já que raramente escritores darão respostas iguais, ou mesmo parecidas, para qualquer uma dessas duas indagações. Em primeiro lugar, porque, na verdade, não têm certeza quanto a essas respostas. Aliás, na área da criação (literária, ou artística, ou científica) ninguém tem certeza de nada. A chamada inspiração ainda é um mistério. Sim, ao contrário do que pensavam os gregos, ela não vem das musas; mas de onde vem, então? Já se identificaram, no cérebro humano, numerosos centros responsáveis por tal ou qual atividade mental; mas o centro da "inspiração", este ainda não foi encontrado e, provavelmente, não o será tão cedo. O que, diga-se de passagem, não é de todo mau. Um pouco de mistério dá gosto à existência. (SCLIAR, 2007, p. 13).

\section{REFERÊNCIAS}

ANDRADE, C. D. de. Depoimento. In: BRITO, J. D. de. (Org.). Como escrevo? 2.ed. São Paulo: Novera, 2007. p. 76-77. 
ANDRADE, M. de. Poesias completas. Edição crítica de Diléa Zanotto Manfio. Belo Horizonte: Itatiaia; São Paulo: EDUSP, 1987.

ANDRESEN, S. de M. B. Poemas escolhidos. Organização de Vilma Arêas. São Paulo: Companhia das Letras, 2004.

BACHELARD, G. A poética do espaço. Tradução de Antonio de Pádua Danesi. São Paulo: Martins Fontes, 1993.

BRITO, J. D. de. (Org.). Como escrevo? 2.ed. São Paulo: Novera, 2007.

BRETON, A. Manifesto do surrealismo. In: TELES, G. M. Vanguarda europeia e modernismo brasileiro: apresentação dos principais poemas, manifestos, prefácios e conferências vanguardistas, de 1857 a 1972. 17.ed. Petrópolis, RJ: Vozes, 2002. p. 174-208.

FERRAZ, M. C. F. Platão: as artimanhas do fingimento. Rio de Janeiro: Relume Dumará, 1999.

HORTA, A. B. Depoimento. In: BRITO, J. D. de. (Org.). Como escrevo? 2.ed. São Paulo: Novera, 2007. p. 44-45.

MELO NeTO, J. C. de. Depoimento. In: BRITO, J. D. de. (Org.). Como escrevo? 2.ed. São Paulo: Novera, 2007. p. 139-140.

PLATÃO. Íon. Introdução, tradução e notas de Victor Jabouille. 2. ed. Lisboa: Inquérito, 1988.

POE, E. A. Poemas e ensaios. Tradução de Oscar Mendes e Milton Amado. Organização, revisão e notas de Carmen Vera Cirne Lima. Rio de Janeiro: Globo, 1985.

STAIGER, E. Conceitos fundamentais da poética. Tradução de Celeste Aída Galeão. Rio de Janeiro: Tempo Brasileiro,1993.

SCLIAR, M. Apresentação: no mundo da idiossincrasia. In: BRITO, J. D. de. (Org.). Como escrevo? 2. ed. São Paulo: Novera, 2007. p. 13-14.

Artigo recebido em 31/08/2012

Aceito para publicação em 24/09/2012 